\title{
Neonatal cholestasis - differential diagnoses, current diagnostic procedures, and treatment
}

\author{
Thomas Götze ${ }^{1}$, Holger Blessing ${ }^{1}$, Christian Grillhösl ${ }^{1}$, Patrick Gerner ${ }^{2}$ and \\ André Hoerning ${ }^{1 *}$
}

${ }^{1}$ Department for Pediatric and Adolescent Medicine, Friedrich-Alexander University of Erlangen-Nuremberg, Erlangen, Germany, ${ }^{2}$ Department for Pediatric and Adolescent Medicine, Albert-Ludwigs-University Freiburg, Freiburg, Germany

Cholestatic jaundice in early infancy is a complex diagnostic problem. Misdiagnosis of cholestasis as physiologic jaundice delays the identification of severe liver diseases. In the majority of infants, prolonged physiologic jaundice represent benign cases of breast milk jaundice, but few among them are masked and caused by neonatal cholestasis (NC) that requires a prompt diagnosis and treatment. Therefore, a prolonged neonatal jaundice, longer than 2 weeks after birth, must always be investigated because an early diagnosis is essential for appropriate management. To rapidly identify the cases with cholestatic jaundice, the conjugated bilirubin needs to be determined in any infant presenting with prolonged jaundice at 14 days of age with or without depigmented stool. Once NC is confirmed, a systematic approach is the key to reliably achieve the diagnosis in order to promptly initiate the specific, and in many cases, life-saving therapy. This strategy is most important to promptly identify and treat infants with biliary atresia, the most common cause of NC, as this requires a hepatoportoenterostomy as soon as possible. Here, we provide a detailed work-up approach including initial treatment recommendations and a clinically oriented overview of possible differential diagnoses in order to facilitate the early recognition and a timely diagnosis of cholestasis. This approach warrants a broad spectrum of diagnostic procedures and investigations including new methods that are described in this review.

Keywords: neonatal cholestasis, neonatal jaundice, conjugated hyperbilirubinemia, biliary atresia, kasai procedure

Specialty section: This article was submitted to Pediatric Gastroenterology and Hepatology, a section of the journal

Frontiers in Pediatrics

Received: 20 September 2014

Accepted: 29 April 2015

Published: 17 June 2015

Citation:

Götze T, Blessing H, Grillhös/ C, Gerner P and Hoerning A (2015)

Neonatal cholestasis - differential diagnoses, current diagnostic procedures, and treatment. Front. Pediatr. 3:43 doi: $10.3389 /$ fped.2015.00043

Abbreviations: AFP, alpha-fetoprotein; ALL, acute lymphoblastic leukemia; ALP, alkaline phosphatase; ALT, alanine aminotransferase; AML, acute myeloid leukemia; ANA, anti-nuclear antibodies; ARPKD, autosomal recessive polycystic kidney disease; AST, aspartate transaminase; ATIII, antithrombin III; $\alpha 1 \mathrm{AT}$, $\alpha 1$-antitrypsin; BA, biliary atresia; BM, bone marrow; BSEP, bile salt export pump; CDG, congenital disorders of glycosylation; CESD, cholesterol ester storage disease; CF, cystic fibrosis; CMV, cytomegalovirus; CrP, C-reactive protein; ECG, electrocardiogram; ERCP, endoscopic retrograde cholangiopancreatography; GALD, gestational alloimmune liver disease; GGT, gamma-glutamyltransferase; HCC, hepatocellular carcinoma; HIV, human immunodeficiency virus; HDL, high-density lipoprotein; $\mathrm{HLH}$, hemophagocytic lymphohistiocytosis HSV, herpes simplex virus; IEF, isoelectrofocusing; IGF, insuline-like growth factor; IGFBP, insuline-like growth factor binding protein; IVIG, intravenous immunoglobulin; LCS1, lymphedema cholestasis syndrome1; LDH, lactate dehydrogenase; LDL, low-density lipoprotein; LIPA, lysosomal lipase acid; MCP, medium chain triglycerides; MRCP, magnetic resonance cholangiopancreatography imaging; MRI, magnetic resonance imaging; NAFLD, non-alcoholic fatty liver disease; NGCH, idiopathic neonatal giant cell hepatitis; NICCD, citrin deficiency; NPD, Niemann-Pick disease; OXSPHOS, respiratory chain oxidative phosphorylation; PBMC, peripheral blood mononuclear cells; PCR, polymerase chain reaction; PFIC, progressive familiary intrahepatic cholestasis; PNAC, parenteral nutrition-associated cholestasis; PNALD, parenteral nutrition-associated liver disease; PTT, partial thromboplastin time; SMA, smooth muscle antibody; TNP, total parenteral nutrition; TSH, thyroid-stimulating hormone; US, ultrasonography; VLCFA, very long chain fatty acids. 


\section{Introduction}

Neonatal physiological jaundice is a common and mostly benign symptom. It typically resolves 2 weeks after birth. Neonatal cholestasis (NC), however, indicated by a conjugated hyperbilirubinemia, is never benign and indicates the presence of a severe underlying condition. A defect of the intrahepatic production or the transmembrane transport of bile, or a mechanical obstruction preventing bile flow leads to an accumulation of bile components in the liver, in the blood and extrahepatic tissues. The incidence of NC is $\sim 1$ in 2500 live births (1). Of the various conditions that can present with $\mathrm{NC}$, biliary atresia (BA) represents the major cause and has been reported to occur in $35-41 \%$ of the cases followed by progressive familial intrahepatic cholestasis (PFIC) (10\%), preterm birth (10\%), metabolic and endocrinological disorders (9-17\%), Alagille syndrome (AS) (2-6\%), infectious diseases (1-9\%), mitochondriopathy (2\%), biliary sludge (2\%), and, finally, idiopathic cases $(13-30 \%)(2,3)$. The rapid diagnosis of BA is paticularly important because early surgical intervention by hepatoportoenterostomy before 2 months of age correlates with better long-term outcome (4-8). Unfortunately, the diagnosis of $\mathrm{NC}$ is often delayed and the average age at diagnosis of BA is about 60 days in USA and Germany $(9,10)$. For these reasons, the fractionated bilirubin must be determined in any infant presenting with prolonged jaundice lasting longer for 14 days of age for term and 21 days for preterm infants with or without depigmented stool. Once conjugated hyperbilirubinemia is identified, a systematic approach is the key to reliably achieve a rapid diagnosis, so that the specific and often life-saving therapy can be promptly initiated. This review offers not only a systematic diagnostic approach but also highlights new diagnostic techniques that have decreased the proportion of idiopathic cases in favor of previously under-reported conditions, such as PFIC, bile acid synthesis defects, and mitochondrial disorders (2). The most frequent causes of $\mathrm{NC}$ are discussed and rare congenital infectious or neonatal disorders are summarized in an adjacent table.

\section{A Diagnostic Approach to NC and Recommendations for Initial Management}

In cases of prolonged neonatal jaundice, the fractionated bilirubin needs to be determined as a first step (Figure 1). A conjugated bilirubin of more than $1 \mathrm{mg} / \mathrm{dL}$ in combination with a total bilirubin of $<5.0 \mathrm{mg} / \mathrm{dL}$, or a conjugated bilirubin fraction of $>20 \%$ of the total, if total bilirubin is $>5.0 \mathrm{mg} / \mathrm{dL}$, indicates NC. A parenteral report of depigmented feces suggests an extrahepatic obstructive process. For clarification, the stool should be seen by a physician in any case.

First of all, conditions or complications that require immediate treatment should be detected. Therefore, a series of basic blood tests need to be performed (as listed at the bottom of Figure 1). Further important initial steps are a fasting ultrasonography, a liver biopsy, and a hepatobiliary scintigraphy. If these tests are inconclusive, then the next step is to undertake an intraoperative cholangiogram or ERCP. In some cases, the liver biopsy may need to be repeated 3-4 months after birth, because several of the diseases follow a dynamic course $(11,12)$. In patients with advanced disease, insufficient hepatic synthetic function and hypovitaminosis, a vitamin K-dependent bleeding disorder may occur. Therefore, an oral supplementation with vitamin $\mathrm{K}(1 \mathrm{mg} /$ day), vitamin A (1500 U/kg/day), vitamin D (cholecalciferol; $500 \mathrm{U} / \mathrm{kg} /$ day), and vitamin E (50 U/kg/day) should be initiated immediately.

\section{Disorders Causing Neonatal Cholestasis Obstructive Bile Duct Disorders}

Biliary atresia is the most frequent and severe cause of NC. In a few cases, it may be part of a syndrome and associated with other congenital malformations such as polysplenia (100\%), situs inversus (50\%), or cardiac anomalies (50\%) and/or vascular malformations, e.g., preduodenal portal vein (60\%) (13).

Biliary atresia is an ascending inflammatory process of the biliary tree leading to progressive obliterative scarring of the extrahepatic and intrahepatic bile ducts, resulting in biliary cirrhosis (14). Only early surgical treatment can stall biliary cirrhosis, which is why rapid identification of BA is crucial.

The exact etiopathogenesis of BA is still unknown and is suggested to involve environmental, infectious, and genetic factors (15). In murine models, pre- or perinatal infections with rotavirus $(16,17)$, cytomegalovirus (15), and reovirus (18) were shown to infect and damage bile duct epithelia giving support to the hypothesis of a primary cholangiotropic viral infection as the initiating event of BA. In humans, however, studies focusing on the detection of viral infections at the time of diagnosis have produced conflicting results (19). In addition, alloimmune events mediated by liver infiltrating maternal effector $\mathrm{T}$ lymphocytes (microchimerism) have also been proposed to play a part in the pathogenesis of BA (20).

Infants with BA present with a conjugated hyperbilirubinemia, elevated liver transaminases including GGT and depigmented or pale stool. An abdominal ultrasound should be performed early to exclude other extrahepatic obstructive lesions such as choledochal cysts, gallstones, or bilary cast. The finding of a small or even absent gallbladder is suggestive of BA. In the majority of the cases, the presence of a structure $\leq 15 \mathrm{~mm}$ in length located in the expected region showing irregular margins without a well-defined wall excludes a normal gallbladder (21). A pre- and postprandial ultrasonography facilitates the demonstration of a physiologic gall bladder contraction. A triangular periportal echogenic structure ( $>3 \mathrm{~mm}$ in thickness) in the liver hilum is called the "triangularcord-sign," a finding associated with high sensitivity (73-100\%) and specificity $(98-100 \%)$ of BA $(22,23)$. In addition, assessing the hepatic arterial subcapsular flow by color Doppler ultrasonography has recently been reported to enable the discrimination of BA from other causes of NC (24).

The diagnostic gold standard of BA is a percutaneous liver biopsy followed by an intraoperative cholangiogram if inconclusive (11). Liver biopsy leads to the diagnosis in 79-98\% of cases (25). Histology is characterized by inflammatory cell infiltrates around bile ducts, portal tract fibrosis, accumulation of bile typically presenting as bile plugs, and bile duct proliferation. ERCP may serve as a reliable and safe additional diagnostic tool (10, $26,27)$ exhibiting a sensitivity of up to $86-92 \%$ and a specificity of $73-94 \%(10,28)$. Hepatobiliary sequence scintigraphy is 


\section{Diagnostic algorithm for neonatal cholestasis}

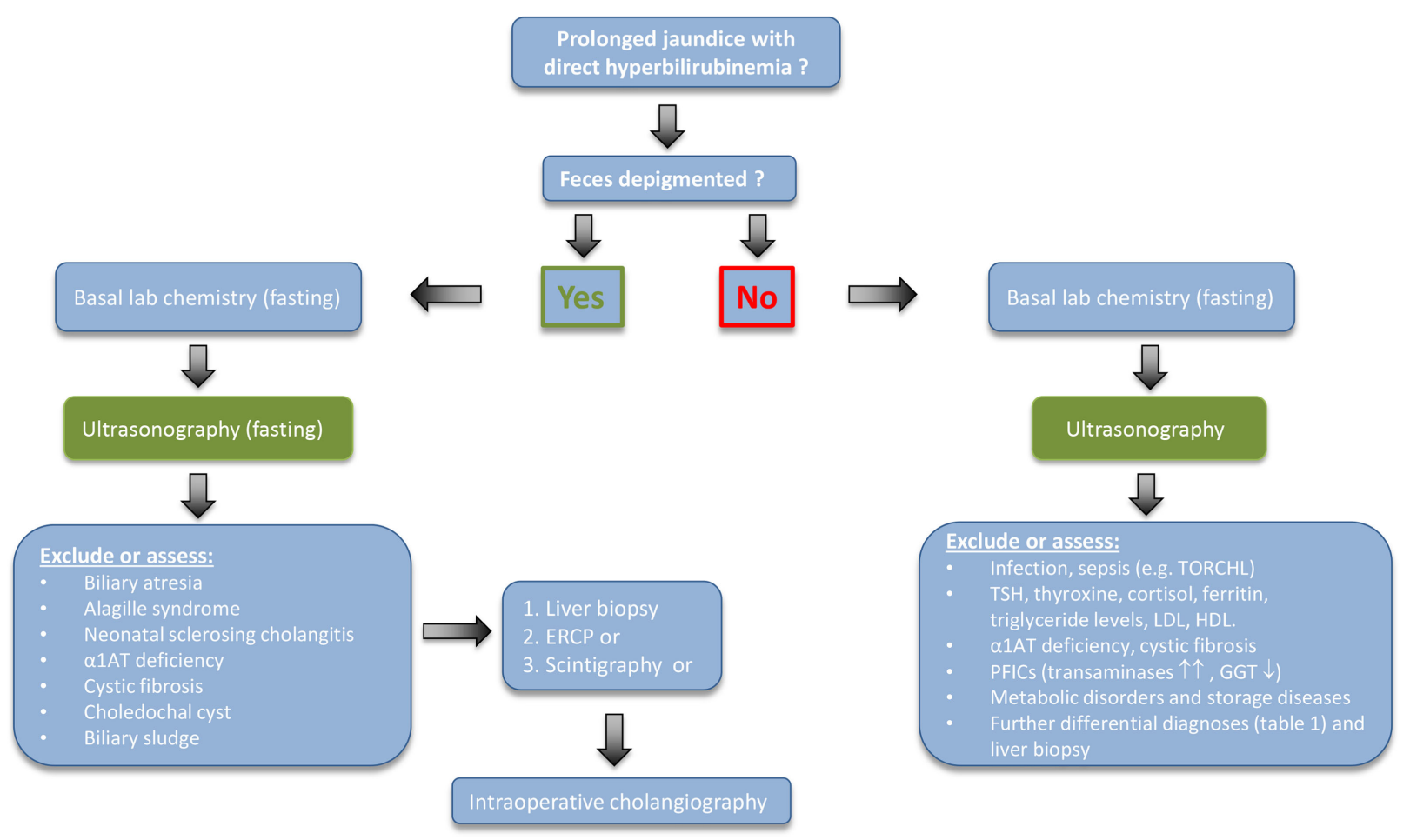

Basal lab chemistry for neonatal cholestasis:

Blood cell count with reticulocytes, total and fractionated bilirubin, coagulation parameters (incl. INR, ATIII), hemolysis parameters, liver transaminases incl. GGT, plasma bile acids, lipase, glucose, lactate, ammonium, CrP.

FIGURE 1 | Diagnostic algorithm for neonatal cholestasis. After confirming direct hyperbilirubinemia, biliary atresia as the most frequent disorder must rapidly be excluded. Hence, the abdominal ultrasound examination (fasting) is of central importance for the evaluation of a cholestatic infant and should be obtained as early as possible. Liver structure, size, dilated bile ducts, gall bladder (size, wall thickness, triangular cord sign), identification of extrahepatic obstructive lesions (e.g., choledochal cyst, gallstones, sludge), ascites, spleen size, situs abnormalities, and vascular malformations should be determined by an experienced operator. If feces is not depigmented and the ultrasound examination remains inconclusive, the diagnostic procedure needs to be quickly expanded as indicated in the text box on the lower right. associated with a high sensitivity (83-100\%) but lacks specificity in many cases $(33-80 \%)$, limiting its usefulness to discriminate between BA and other non-surgical conditions (29). Additional non-invasive and other quite promising studies focus on the identification of serum markers that may reliably distinguish BA from other forms of $\mathrm{NC}(30,31)$. Song et al. (30) found that the expression of the apolipoproteins Apo C-II and Apo CIII to be upregulated in the serum of infants with BA, while Zahm et al. (31) analyzed elevated patterns of circulating microRNAs and identified the miR-200b/429 cluster as a potential biomarker.

Treatment of BA consists of a hepatoportoenterostomy to enable biliary drainage (32). The success rate of this procedure is closely associated with the age of the infant at time of surgery (4, 7-9). Most reliable predictors for successful surgery and long-term outcome with the native liver are the normalization of conjugated bilirubin and AST 2 months after surgery (33). Although the problem of late diagnosis has been defined for some years, surgery within the first 2 months of age has still not been universally achieved in many centers/countries $(9,10,34)$. In Taiwan, a stool color card system led to a decline of late referral (35), which is one reason why it is regarded as a simple and promising screening approach to early the identification of BA (36).

Alagille syndrome accounts for 2-6\% of infants with NC $(2,3)$. Liver histology typically demonstrates a paucity of interlobular biliary ducts. Bile ductular proliferation as observed in BA is absent. Mutations in the JAG-1 gene are responsible for more than $90 \%$ of cases of AS; others have mutations in the gene encoding for the NOTCH-2 receptor $(37,38)$. The main diagnostic criteria of AS are typical facial signs such as a broad forehead, deep set eyes, and a pointed chin giving the face a triangular appearance (77-98\%), an ocular embryotoxon (61-88\%), cardiac abnormalities (85-97\%), and butterfly vertebrae (39-87\%). Minor criteria are growth (50-87\%) and/or developmental delay (16-52\%), renal disease such as renal cysts, renal artery stenosis, and tubular acidosis (40-73\% cases), and exocrine pancreatic insufficiency (40\%) $(39,40)$. Early development of hepatocellular carcinoma (HCC) may occur regardless of the presence of cirrhosis. Thus, patients 
with AS should be screened for HCC with alpha-fetoprotein and ultrasonography every 6 months.

Cystic, ectatic alterations of the intra- and/or extrahepatic bile duct system represent a further cause of NC. Choledochal cysts account for $2-3 \%$ of infants with NC and are surgically treatable (2). According to Todani, five anatomic variants have been described, but most infants show dilatation of the common bile duct (Todani type 1, 50-80\% of biliary cysts) (41). Caroli's disease is associated with multifocal, segmental, and saccular or fusiform dilatations of the medium and large intrahepatic bile ducts without affecting the common bile duct (28). These malformations may be limited to one liver lobe, most commonly the left one. Involvement of both the medium intrahepatic bile ducts (Caroli's disease) and the small interlobular bile ducts results in the more frequent Caroli syndrome. Caroli syndrome is associated with ciliopathies and frequently presents with congenital hepatic fibrosis. This condition may also include renal abnormalities, e.g., autosomal recessive polycystic kidney disease (ARPKD), juvenile nephronophtisis, Joubert syndrome, and others (42). The diagnosis is established by ultrasound, ERCP, and/or MRCP (28). Administration of ursodeoxycholic acid (UDCA) decreases bile stasis and prevents the formation of intrahepatic cholelithiasis. Liver transplantation is a curative therapy (43).

Neonatal onset of sclerosing cholangitis is characterized at ERCP by a varying degree of stenotic and focally dilated intrahepatic bile ducts with rarification of segmental branches $(44,45)$. Liver transplantation is the only treatment option. In a few cases, it is associated with ichthyosis, and hence termed as neonatal ichthyosis and sclerosing cholangitis (NISCH) syndrome. $\mathrm{NISCH}$ is caused by mutations of the CLDN1 gene encoding for Claudin-1, a tightjunction protein. The Claudin-1 defect leads to an increased paracellular permeability and hepatocellular damage caused by toxicity of paracellular bile regurgitation (46).

Idiopathic neonatal giant cell hepatitis is a differential diagnosis after exclusion of all other causes of NC (47). Histology findings are non-specific, and include the formation of syncytial multinucleated hepatic giant cells, variable inflammation, with infiltration of lymphocytes, neutrophils, and eosinophils and lobular cholestasis - changes that are also seen in other conditions, such as $\alpha 1$ ATD or PFIC (47).

The non-cholestatic entities Dubin-Johnson syndrome (defect in the MRP2 gene) (48) and Rotor syndrome (defect in the OATP1B1/OATP1B3 gene) (49) need to be distinguished from NC. These conditions also manifest with direct hyperbilirubinemia but the excretion of serum bile acid is unimpaired. In Dubin-Johnson syndrome, biliary excretion of conjugated bilirubin via the MRP-2 channel is impaired, whereas in Rotor syndrome, there is a defect in the hepatic storage of conjugated bilirubin, which then leaks into the plasma. Diagnosis and differentiation between these conditions are achieved by urinary coproporphyrin analysis $(50,51)$.

\section{Alterations in the Hepatocellular Bile Acid Transport System}

The PFIC conditions are a heterogeneous group of autosomal recessive disorders characterized by mutations in hepatocellular bile acid transport-system genes leading to impaired bile formation. About $10 \%$ of infants that present with NC suffer from PFIC-1 and -2 (2). Three types of PFIC have been identified: PFIC1 and PFIC2 usually appear in the first months of life, whereas onset of PFIC3 typically arises later in childhood. Infants with PFIC1 or PFIC2 present with NC, therapy resistant pruritus and coagulopathy due to vitamin $\mathrm{K}$ malabsorption. A characteristic feature of these conditions is that the serum gammaglutamyltransferase activity is normal or even low in PFIC1 and PFIC2 patients, but elevated in PFIC3 patients. PFIC1 is caused by impaired bile salt secretion due to defects in the ATP8B1 gene that encodes the FIC1 protein - a protein that stabilizes the hepatocellular membrane by transfer of aminophospholipids (52). Mutations in the FIC1 gene also cause benign recurrent intrahepatic cholestasis (BRIC1, Summerskill syndrome), which is characterized by recurrent episodes of cholestasis that may not necessarily lead to liver cirrhosis (53). Mutations in the ABCB11 gene encoding the bile salt export pump (BSEP) protein lead to PFIC2 $(52,54)$. Defects in ABCB4 that encodes the multidrug resistance 3 protein (MDR3) impair biliary phospholipid secretion and result in PFIC3 $(52,55)$. Diagnosis is based on immunostaining of BSEP (PFIC2) and MDR3 (PFIC3) in liver biopsies as well as the analysis of biliary lipid composition and genotyping for PFI mutations causing PFIC1. UDCA helps to postpone biliary cirrhosis in the PFIC conditions. An early partial external biliary diversion normalizes serum bile acids and relieves pruritus for children with PFIC1 and 2 (56). This procedure decelerates disease progression until liver transplantation is needed.

\section{Metabolic Disorders and Storage Diseases}

Neonatal cholestasis is caused by a number of metabolic disorders with cystic fibrosis (CF) and alpha-1-antitrypsin deficiency $(\alpha 1 A T D)$ being the most common. Although infants with $\mathrm{CF}$ are more likely to present with meconium ileus or steatorrhea with failure to thrive, $5 \%$ of patients with CF manifest with NC (57). $\alpha 1$ ATD is inherited in an autosomal recessive trait and, similarly to CF, estimated to affect 1 in 2500-5000 children (58). The proportion of infants with $\alpha 1 \mathrm{ATD}$ in cases of NC is about $1-17 \%(2,3)$. A pathologic polymerization of AAT within the endoplasmatic reticulum results in an intrahepatocellular accumulation of the misfolded $\alpha 1 \mathrm{AT}$ molecule leading to progredient liver fibrosis/cirrhosis. Hence, serum $\alpha 1 \mathrm{AT}$ concentration is typically decreased. However, a normal $\alpha 1 \mathrm{AT}$ level does not exclude the diagnosis because $\alpha 1 \mathrm{AT}$ is an acute phase protein and may be raised by inflammatory processes. Therefore, the deficient $\alpha 1$ AT-variant needs to be identified by protease inhibitor (PI) typing using polyacrylamide isoelectric focusing (59). While liver involvement in childhood is mainly associated with the PI-ZZ genotype (60), the PI-MZ and PI-SZ types are both characterized by respiratory symptoms (e.g., recurrent pneumothoraces) (61). The pathogenesis of the pulmonary manifestation differs from liver disease. In the lung, severe deficiency of the elastase inhibitor AAT results in an uninhibited proteolytic activity of elastase predisposing to a chronic obstructive disease with development of a panacinar emphysema. However, within the first two decades of life, liver dysfunction represents the major threat whereas pulmonary disease in not a major concern (62). Liver transplantation is curative and the treatment of choice for $\alpha 1 \mathrm{ATD}$. 
TABLE 1 | Summary of the differential diagnoses and diagnostic approaches.

\begin{tabular}{ll}
\hline Disease & Diagnostic approach \\
\hline BILE DUCT OBSTRUCTION & \\
$\begin{array}{l}\text { Structural } \\
\text { Biliary atresia }\end{array}$ & US, liver biopsy, ERCP, hepatobiliary scintigraphy, intraoperative cholangiogram \\
Alagille syndrome & $\begin{array}{l}\text { Typical facial features, chest x-ray (butterfly vertebrae), ophthalmology, echo, liver } \\
\text { biopsy, cholesterol } \uparrow\end{array}$ \\
Choledochal cyst & US, ERCP, MRCP \\
Caroli's disease/syndrome & US (liver and kidneys), ERCP, MRCP if >1 year of age, PKHD1 gene (ARPKD) \\
Gallstones or biliary sludge & US, ERCP \\
Neonatal sclerosing & ERCP, liver biopsy
\end{tabular}

Genetic analysis

cholangitis

Hepatocellular

Idiopathic neonatal giant cell

Histological diagnosis after exclusion of other causes

hepatitis (NGCH)

Progressive familial

intrahepatic cholestasis (PFIC)

Liver biopsy, genetic analysis

GGT $(\downarrow-\rightarrow$ in types $1+2, \uparrow$ in type 3$)$

\section{METABOLIC DISORDERS, STORAGE DISEASES, AND OTHERS}

Cystic fibrosis

A1AT deficiency

Inborn errors of bile acid

synthesis

Gaucher disease

Niemann-Pick type C

Wolman disease, LAL

deficiency

Mitochondrial disorders

Neonatal Intrahepatic cholestasis caused by citrin deficiency (NICCD)

Peroxismal disorders

(Zellweger's spectrum and others)

Tyrosinemia

Classic galactosemia

Congenital disorders of glycosylation (CDG)

\section{ENDOCRINE DISORDERS}

Hypothyroidism

Newborn screening (not in Germany), trypsinogen content in stool, genetic analysis

A1AT levels $\downarrow$

$\mathrm{PI}$ analysis (type ZZ, SZ, MZ)

Urinary bile acid analysis, molecular-genetic analysis

AP $\uparrow, \beta$-glucocerebrosidase $\downarrow$, chitotriosidase $\uparrow$, BM biopsy: "crinkled paper" cytoplasm and glycolipid-laden macrophages, foam cells (Gaucher cells)

Filipin positive reaction (detection of cholesterol in fibroblasts), genetic testing, chitotriosidase $\uparrow$

Lysosomal lipase acid $\downarrow \downarrow$ in PBMC

Fasting and postprandial lactate, plasma lactate/pyruvate ratio $>20$, functional assays, genetics

Citrulline $\uparrow, \alpha$-fetoprotein $\uparrow$, and ferritin $\uparrow$

Zellweger's: Typical craniofacial dysmorphism, mental retardation, hepatomegaly, glomerulocystic kidney disease, cataracts, pigmentary retinopathy

VLCFA $\uparrow$, pattern of plasmalogenes, phytanic acid, pristanic acid

Newborn screening, urinary excretion of succinylacetone $\uparrow, 4$-hydroxyphenylketones, and $\delta$-aminolevulinic acid $\uparrow$ Cave: $\operatorname{HCC}(\mathrm{AFP} \uparrow)(83)$

Newborn screening, galactose-1-phosphate uridyl transferase activity in red blood cells $\downarrow \downarrow$

Dysmorphic facies, convergent strabism, inverted mammils, mental retardation, seizures, dystrophy, hepatomegaly, hepatic fibrosis/steatosis, cyclic vomiting and diarrhea, coagulopathy, protein losing enteropathy with hypoalbuminemia (CDG1b) Lab chemistry: Triglycerides $\uparrow$, ATIII $\downarrow$, factor XI $\downarrow$, protein C and S $\downarrow$, Transferrin IEF

Panhypopituitarism

\section{TOXIC OR SECONDARY DISORDERS}

Parenteral

Exclusion of other causes

Newborn screening (TSH $\uparrow)$

nutrition-associated

cholestasis (PNAC), drugs

(e.g., anticonvulsants)
Torbenson (47)

Binder et al. (91), Karnsakul et al. (92)

Wildhaber (71), Mieli-Vergani and Vergani (4)

JAG1, NOTCH2 genes; Vajro et al. (39),

Turnpenny and Ellard (40), Kamath et al. (38)

Todani et al. (41)

Adeva et al. (72), Harring et al. (43), Krall et al. (73)

Baker et al. (44), Girard et al. (45)

ABCB4, ABCB11, ATP8B1; Jacquemin (52), Kubitz et al. (54)

CFTR gene; Sokol and Durie (57)

SERPINA1 gene analysis for prenatal diagnosis; Perlmutter (59), Fregonese and Stolk (58)

Clayton et al. (66); BAAT and SLC27A5 gene, Setchell et al. (67)

Rosenbloom et al. (69)

NPC1, NPC2 gene; Patterson et al.(74)

LIPA gene; Zhang and Porto (75)

SC01, SUCLG1, BCS1L, POLG1, C10ORF2, DGUOK, and MPV17 gene mutations; Fellman and Kotarsky (76), Wong et al. (77)

SLC25A13 gene; Lu et al. (78), Kimura et al. (79), Song et al. (80)

Moser et al. $(81,82)$

FAH gene, de Laet et al. (84)

Mayatepek et al. (85)

Jaeken (86), Freeze (87, 88), Linssen et al. (89)

Hsieh et al. (93) 


\begin{tabular}{|c|c|c|}
\hline Disease & Diagnostic approach & Genetic analysis \\
\hline \multicolumn{3}{|c|}{ IMMUNOLOGICAL DISORDERS } \\
\hline $\begin{array}{l}\text { Gestational alloimmune liver } \\
\text { disease (GALD) }\end{array}$ & $\begin{array}{l}\text { Ferritin } \uparrow \uparrow ~(>1000 \mu \mathrm{g} / \mathrm{L}) \text {, buccal mucosal biopsy and liver biopsy (iron deposition?), } \\
\text { MRI (extrahepatic iron deposition?) }\end{array}$ & Rand et al. (94) \\
\hline $\begin{array}{l}\text { Neonatal lupus } \\
\text { erythematosus }\end{array}$ & $\begin{array}{l}\text { Transplacental passage of ANA, anti-RoSSA, anti-La/SSB, anti-U1RNP antibodies } \\
\text { Echo, ECG (congenital heart block) }\end{array}$ & Hon and Leung (95) \\
\hline $\begin{array}{l}\text { Haemophagocytic } \\
\text { lymphohistiocytosis (HLH) }\end{array}$ & $\begin{array}{l}\text { Fever }(>7 \text { days), hepatosplenomegaly with liver dysfunction, pancytopenia, sCD25 } \\
(>2400 \mu \mathrm{g} / \mathrm{mL}) \text {, ferritin }(>500 \mu \mathrm{g} / \mathrm{L}) \text {, triglycerides }(>3 \mathrm{mmol} / \mathrm{L}) \text {, hypofibrinogenemia } \\
(<150 \mathrm{mg} / \mathrm{dL}) \text {, serum cytokine levels of both IFNg }(>75 \mathrm{pg} / \mathrm{ml})+\mathrm{IL}-10(>60 \mathrm{pg} / \mathrm{ml}) \uparrow\end{array}$ & Lehmberg and Ehl (96), Xu et al. (97) \\
\hline \multicolumn{3}{|l|}{ INFECTIOUS DISORDERS } \\
\hline $\begin{array}{l}\text { Sepsis, urinary tract } \\
\text { infections, TORCH, hepatitis }\end{array}$ & $\begin{array}{l}\text { PCR, microbiology, serology, ophthalmologic examination (toxoplasmosis, CMV, } \\
\text { rubella) }\end{array}$ & $\begin{array}{l}\text { Kosters and Karpen (98), Bellomo-Brandao } \\
\text { et al. (99), Robino et al. (100) }\end{array}$ \\
\hline
\end{tabular}

A-E, EBV, HIV, Echo, adeno,

coxsackie virus, Parvo B19,

HHV6-8, VZV, syphilis,

leptospirosis

VASCULAR MALFORMATIONS

$\begin{array}{ll}\begin{array}{l}\text { Portosystemic shunts } \\ \text { Multiple hemangioma }\end{array} & \text { US, MRI, LE } \uparrow \text {, unexplained galactosemia, hyperammonemia, manganemia } \\ \begin{array}{l}\text { Congestive heart failure } \\ \text { MISCELLANEOUS }\end{array} & \text { Echo (heart anomalies, e.g., in Down syndrome), US, liver histology } \\ \text { Genetic disorders } & \text { Trisomy 21, Trisomy 18 } \\ \text { ARC syndrome } & \text { Arthrogryposis multiplex congenita, facial dysmorphia, dystrophia, renal tubular } \\ & \text { acidosis, cholestasis, platelet dysfunction, ichthyosis } \\ \text { Aagenes syndrome } & \text { Lymphedema cholestasis syndrome 1 (LCS1) } \\ \text { Microvillus inclusion disease } & \text { Life threatening congenital watery diarrhea of secretory type. Histology: microvillus } \\ \text { (MVID) } & \text { atrophy, detection of PAS+ granules and CD10+ lining in LM and inclusion bodies } \\ & \text { in EM }\end{array}$

Neonatal leukemia

$A M L \gg A L L$

Bernard et al. (101)
Avagyan et al. (102), Horii et al. (103)
Arnell and Fischler (104)

VPS33B gene; Smith et al. (105), Eastham et al. (106)

Drivdal et al. (107)

MYO5B gene, Ruemmele et al. (108)

Van der Linden et al. (109)

AFP, alpha-fetoprotein; ALP, alkaline phosphatase; BM, bone marrow; DD, differential diagnosis; ERCP, endoscopic retrograde cholangiopancreaticography; EM, electronmicroscopy; HCC, hepatocellular carcinoma; MRI, magnetic resonance imaging; LE, liver enzymes; LM, light microscopy; PBMC, peripheral blood mononuclear cell; US, ultrasound; VLCFA, very long chain fatty acids.

Inherited disorders of bile acid synthesis cause $\sim 2 \%$ of persistent cholestasis in infants (63). Cholestasis is thought to result from an imbalance and inadequate production of primary bile acids. This results in an accumulation of aberrant hepatotoxic bile acids and intermediary metabolites leading to an impaired bile flow (64). In contrast to other causes of NC, the serum bile acid levels are normal. Enzyme defects result in a specific pattern of metabolites that can be assessed by analysis of urinary cholanoids (bile acids and bile alcohols) $(65,66)$. Molecular-genetic analysis of the genes encoding the bile acid-CoA amino acid $N$ acyltransferase (BAAT) and bile acid-CoA ligase (SLC27A5) is possible (67). Peroral treatment with primary bile acids (cholic acid, not UDCA) leads to normalization of liver function in most patients (68).

Storage disorders and disorders of lipid metabolism, including Gaucher disease and Niemann-Pick type C disease (NPD), contribute to $\sim 1 \%$ of infants with NC (2). In Gaucher disease, deficiency of the lysosomal $\beta$-glucocerebrosidase results in the impaired recycling of cellular glycolipids. The consequence is an excessive storage of glucocerebroside in the liver, lung, spleen, bone, and bone marrow (69). Infants develop anemia, thrombocytopenia, hepatosplenomegaly, and, in some cases, bone infarcts and aseptic bone necrosis. Therapeutic options for type I Gaucher disease are an enzyme-replacement therapy or a substrate reduction therapy with oral Miglustat that inhibits the glucosylceramide synthase (70). The diagnostic procedures for the confirmation of Gaucher disease and NPD are summarized in

\section{Table 1}

Wolman disease and cholesterol ester storage disease (CESD) are rare autosomal recessive disorders with an estimated incidence of 1 in 40,000 live births (75). Their identification is especially important as an enzyme-replacement therapy with human recombinant lysosomal acid lipase (LAL) is now available and improves the natural course, thus offering a possibility for longterm survival $(78,79)$. Wolman disease may manifest as NC, and clinically appears within the first 2-4 months of age with hepatosplenomegaly, liver fibrosis, adrenal calcification and insufficiency, malabsorption, diarrhea, and poor weight gain as common features. Wolman disease usually takes a fatal course, with death within 12 months of age. Both diseases result from a deficiency of the LAL that usually catalyzes the degradation of cholesteryl esters and triglycerides that are delivered to the liposomes by a LDL-receptor mediated endocytosis. LALdeficiency thus leads to elevated serum triglycerides and LDL, an intralysosomal accumulation of cholesteryl esters, triglycerides, and other lipids in various tissues, predominantly in macrophages. Whereas a loss of function mutation in the LIPA gene causes Wolman disease, CESD results when residual activity 
of the LAL enzyme is retained. Symptoms of CESD may be nonspecific in early infancy. It is felt that the incidence of CESD is currently underestimated as it easily can be misdiagnosed as nonalcoholic fatty liver disease (NAFLD) later in childhood (75). Both entities show microvesicular steatosis on liver histology. Identification of Maltese cross-type birefringence (stored liquid crystals of cholesteryl esters) on frozen sections, and/or the detection of the lysosomal-associated membrane proteins 1 and 2 (LAMP) around the lipid droplets suggest CESD (110). Diagnosis is based on LIPA gene sequencing and assessment of LAL levels in PBMCs (111).

Mitochondrial disorders manifesting early in life often have a hepatic involvement, and in the majority of cases more than one organ such as the muscle or the nervous system is affected (76). A recent study reported that $\sim 2 \%$ of infants with NC suffer from a mitochondrial hepatopathy (2). Clinical manifestations and the degree of organ involvement varies. This condition often remains undetected until exacerbation is precipitated, typically following an intercurrent viral infection. Histological findings include glycogen deprivation of the hepatocytes, microvesicular lipid accumulation, and signs of fibrosis/cirrhosis. Among the mitochondriopathies, Pearson syndrome is most often presents

\section{References}

1. McKiernan PJ. Neonatal cholestasis. Semin Neonatol (2002) 7(2):153-65. doi:10.1053/siny.2002.0103

2. Hoerning A, Raub S, Dechene A, Brosch MN, Kathemann S, Hoyer PF, et al. Diversity of disorders causing neonatal cholestasis - the experience of a tertiary pediatric center in Germany. Front Pediatr (2014) 2:65. doi:10.3389/ fped.2014.00065

3. Mieli-Vergani G, Howard ER, Portman B, Mowat AP. Late referral for biliary atresia - missed opportunities for effective surgery. Lancet (1989) 1(8635):421-3. doi:10.1016/S0140-6736(89)90012-3

4. Mieli-Vergani G, Vergani D. Biliary atresia. Semin Immunopathol (2009) 31(3):371-81. doi:10.1007/s00281-009-0171-6

5. Sokol RJ, Mack C, Narkewicz MR, Karrer FM. Pathogenesis and outcome of biliary atresia: current concepts. J Pediatr Gastroenterol Nutr (2003) 37(1):4-21. doi:10.1097/00005176-200307000-00003

6. Sokol RJ, Shepherd RW, Superina R, Bezerra JA, Robuck P, Hoofnagle JH. Screening and outcomes in biliary atresia: summary of a National Institutes of Health workshop. Hepatology (2007) 46(2):566-81. doi:10.1002/hep.21790

7. Serinet MO, Wildhaber BE, Broue P, Lachaux A, Sarles J, Jacquemin E, et al. Impact of age at kasai operation on its results in late childhood and adolescence: a rational basis for biliary atresia screening. Pediatrics (2009) 123(5):1280-6. doi:10.1542/peds.2008- 1949

8. Lien TH, Chang MH, Wu JF, Chen HL, Lee HC, Chen AC, et al. Effects of the infant stool color card screening program on 5-year outcome of biliary atresia in Taiwan. Hepatology (2011) 53(1):202-8. doi:10.1002/hep.24023

9. Wadhwani SI, Turmelle YP, Nagy R, Lowell J, Dillon P, Shepherd RW. Prolonged neonatal jaundice and the diagnosis of biliary atresia: a singlecenter analysis of trends in age at diagnosis and outcomes. Pediatrics (2008) 121(5):e1438-40. doi:10.1542/peds.2007-2709

10. Petersen C, Meier PN, Schneider A, Turowski C, Pfister ED, Manns MP, et al. Endoscopic retrograde cholangiopancreaticography prior to explorative laparotomy avoids unnecessary surgery in patients suspected for biliary atresia. J Hepatol (2009) 51(6):1055-60. doi:10.1016/j.jhep.2009.06.025

11. Moyer V, Freese DK, Whitington PF, Olson AD, Brewer F, Colletti RB, et al. Guideline for the evaluation of cholestatic jaundice in infants: recommendations of the north American society for pediatric gastroenterology, hepatology and nutrition. J Pediatr Gastroenterol Nutr (2004) 39(2):115-28. doi:10.1097/ 00005176-200408000-00001 with liver manifestations (76). The diagnostic work-up should include genetic testing as well as functional assessment of the respiratory chain enzyme complexes in both liver and muscle biopsies (77). Of note, liver injury caused by any NC can secondarily affect OXPHOS activity. As a consequence, a compromised mtDNA complex activity may, therefore, not necessarily serve as proof for a mitochondriopathy related liver disease. Further rare metabolic causes are summarized in Table 1.

\section{Conclusion}

A variety of disorders can present with cholestasis during the neonatal period. In all cases of neonatal jaundice lasting longer than 14 days, the measurement of fractionated bilirubin must be performed. BA is the most common entity leading to NC. It must be differentiated from other causes of cholestasis promptly because early surgical intervention before 2 months of age results in a better patient outcome. Previously underdiagnosed disorders comprise the PFICs, hepatic mitochondriopathies, and also, presumably, the LAL deficiency that causes Wolman disease and CESD. Early identification of the possible disorders is important, and prompt referral to a pediatric hepatology unit is essential.

12. Landing BH, Wells TR, Ramicone E. Time course of the intrahepatic lesion of extrahepatic biliary atresia: a morphometric study. Pediatr Pathol (1985) 4(3-4):309-19. doi:10.3109/15513818509026904

13. Davenport M, Tizzard SA, Underhill J, Mieli-Vergani G, Portmann B, Hadzic $\mathrm{N}$. The biliary atresia splenic malformation syndrome: a 28-year single-center retrospective study. J Pediatr (2006) 149(3):393-400. doi:10.1016/j.jpeds.2006. 05.030

14. Mack CL, Sokol RJ. Unraveling the pathogenesis and etiology of biliary atresia. Pediatr Res (2005) 57(5 Pt 2):87R-94R. doi:10.1203/01.PDR.0000159569. 57354.47

15. Mack CL, Feldman AG, Sokol RJ. Clues to the etiology of bile duct injury in biliary atresia. Semin Liver Dis (2012) 32(4):307-16. doi:10.1055/ s-0032-1329899

16. Zheng S, Zhang H, Zhang X, Peng F, Chen X, Yang J, et al. CD8+ T lymphocyte response against extrahepatic biliary epithelium is activated by epitopes within NSP4 in experimental biliary atresia. Am J Physiol Gastrointest Liver Physiol (2014) 307(2):G233-40. doi:10.1152/ajpgi.00099.2014

17. Feng J, Yang J, Zheng S, Qiu Y, Chai C. Silencing of the rotavirus NSP4 protein decreases the incidence of biliary atresia in murine model. PLoS One (2011) 6(8):e23655. doi:10.1371/journal.pone.0023655

18. Nakashima T, Hayashi T, Tomoeda S, Yoshino M, Mizuno T. Reovirus type2-triggered autoimmune cholangitis in extrahepatic bile ducts of weanling DBA/1J mice. Pediatr Res (2014) 75(1-1):29-37. doi:10.1038/pr.2013.170

19. Feldman AG, Mack CL. Biliary atresia: cellular dynamics and immune dysregulation. Semin Pediatr Surg (2012) 21(3):192-200. doi:10.1053/j.sempedsurg. 2012.05.003

20. Muraji T, Hosaka N, Irie N, Yoshida M, Imai Y, Tanaka K, et al. Maternal microchimerism in underlying pathogenesis of biliary atresia: quantification and phenotypes of maternal cells in the liver. Pediatrics (2008) 121(3):517-21. doi:10.1542/peds.2007-0568

21. Aziz S, Wild Y, Rosenthal P, Goldstein RB. Pseudo gallbladder sign in biliary atresia - an imaging pitfall. Pediatr Radiol (2011) 41(5):620-6. doi:10.1007/ s00247-011-2019-1

22. Dehghani SM, Haghighat M, Imanieh MH, Geramizadeh B. Comparison of different diagnostic methods in infants with cholestasis. World J Gastroenterol (2006) 12(36):5893-6.

23. Takamizawa S, Zaima A, Muraji T, Kanegawa K, Akasaka Y, Satoh S, et al. Can biliary atresia be diagnosed by ultrasonography alone? J Pediatr Surg (2007) 42(12):2093-6. doi:10.1016/j.jpedsurg.2007.08.032 
24. El-Guindi MA, Sira MM, Konsowa HA, El-Abd OL, Salem TA. Value of hepatic subcapsular flow by color Doppler ultrasonography in the diagnosis of biliary atresia. J Gastroenterol Hepatol (2013) 28(5):867-72. doi:10.1111/jgh. 12151

25. Russo P, Magee JC, Boitnott J, Bove KE, Raghunathan T, Finegold M, et al. Design and validation of the biliary atresia research consortium histologic assessment system for cholestasis in infancy. Clin Gastroenterol Hepatol (2011) 9(4): 357-62.e2. doi:10.1016/j.cgh.2011.01.003

26. Shteyer E, Wengrower D, Benuri-Silbiger I, Gozal D, Wilschanski M, Goldin E. Endoscopic retrograde cholangiopancreatography in neonatal cholestasis. J Pediatr Gastroenterol Nutr (2012) 55(2):142-5. doi:10.1097/ MPG.0b013e318259267a

27. Shanmugam NP, Harrison PM, Devlin J, Peddu P, Knisely AS, Davenport M, et al. Selective use of endoscopic retrograde cholangiopancreatography in the diagnosis of biliary atresia in infants younger than 100 days. J Pediatr Gastroenterol Nutr (2009) 49(4):435-41. doi:10.1097/MPG. ob013e3181a8711f

28. Keil R, Snajdauf J, Rygl M, Pycha K, Kotalova R, Drabek J, et al. Diagnostic efficacy of ERCP in cholestatic infants and neonates - a retrospective study on a large series. Endoscopy (2010) 42(2):121-6. doi:10.1055/s-0029-1215372

29. Feldman AG, Sokol RJ. Neonatal cholestasis. Neoreviews (2013) 14(2):e63-73. doi:10.1542/neo.14-2-e63

30. Song Z, Dong R, Fan Y, Zheng S. Identification of serum protein biomarkers in biliary atresia by mass spectrometry and enzyme-linked immunosorbent assay. J Pediatr Gastroenterol Nutr (2012) 55(4):370-5. doi:10.1097/MPG. 0b013e31825bb01a

31. Zahm AM, Hand NJ, Boateng LA, Friedman JR. Circulating microRNA is a biomarker of biliary atresia. J Pediatr Gastroenterol Nutr (2012) 55(4):366-9. doi:10.1097/MPG.0b013e318264e648

32. Kasai M. Treatment of biliary atresia with special reference to hepatic portoenterostomy and its modifications. Prog Pediatr Surg (1974) 6:5-52.

33. Goda T, Kawahara H, Kubota A, Hirano K, Umeda S, Tani G, et al. The most reliable early predictors of outcome in patients with biliary atresia after kasai's operation. J Pediatr Surg (2013) 48(12):2373-7. doi:10.1016/j.jpedsurg.2013. 08.009

34. Hoerning A, Raub S, Neudorf U, Muntjes C, Kathemann S, Lainka E, et al. Pulse oximetry is insufficient for timely diagnosis of hepatopulmonary syndrome in children with liver cirrhosis. J Pediatr (2014) 164(3): 546-52.e1-2. doi:10.1016/j.jpeds.2013.10.070

35. Chen SM, Chang MH, Du JC, Lin CC, Chen AC, Lee HC, et al. Screening for biliary atresia by infant stool color card in Taiwan. Pediatrics (2006) 117(4):1147-54. doi:10.1542/peds.2005-1267

36. Tseng JJ, Lai MS, Lin MC, Fu YC. Stool color card screening for biliary atresia. Pediatrics (2011) 128(5):e1209-15. doi:10.1542/peds.2010-3495

37. McDaniell R, Warthen DM, Sanchez-Lara PA, Pai A, Krantz ID, Piccoli DA, et al. NOTCH2 mutations cause Alagille syndrome, a heterogeneous disorder of the notch signaling pathway. Am J Hum Genet (2006) 79(1):169-73. doi:10. $1086 / 505332$

38. Kamath BM, Bauer RC, Loomes KM, Chao G, Gerfen J, Hutchinson A, et al. NOTCH2 mutations in Alagille syndrome. J Med Genet (2012) 49(2):138-44. doi:10.1136/jmedgenet-2011-100544

39. Vajro P, Ferrante L, Paolella G. Alagille syndrome: an overview. Clin Res Hepatol Gastroenterol (2012) 36(3):275-7. doi:10.1016/j.clinre.2012.03.019

40. Turnpenny PD, Ellard S. Alagille syndrome: pathogenesis, diagnosis and management. Eur J Hum Genet (2012) 20(3):251-7. doi:10.1038/ejhg.2011.181

41. Todani T, Watanabe Y, Narusue M, Tabuchi K, Okajima K. Congenital bile duct cysts: classification, operative procedures, and review of thirty-seven cases including cancer arising from choledochal cyst. Am J Surg (1977) 134(2):263-9. doi:10.1016/0002-9610(77)90359-2

42. Shorbagi A, Bayraktar Y. Experience of a single center with congenital hepatic fibrosis: a review of the literature. World J Gastroenterol (2010) 16(6):683-90. doi:10.3748/wjg.v16.i6.683

43. Harring TR, Nguyen NT, Liu H, Goss JA, O'Mahony CA. Caroli disease patients have excellent survival after liver transplant. J Surg Res (2012) 177(2):365-72. doi:10.1016/j.jss.2012.04.022

44. Baker AJ, Portmann B, Westaby D, Wilkinson M, Karani J, Mowat AP. Neonatal sclerosing cholangitis in two siblings: a category of progressive intrahepatic cholestasis. J Pediatr Gastroenterol Nutr (1993) 17(3):317-22. doi:10.1097/ 00005176-199310000-00016
45. Girard M, Franchi-Abella S, Lacaille F, Debray D. Specificities of sclerosing cholangitis in childhood. Clin Res Hepatol Gastroenterol (2012) 36(6):530-5. doi:10.1016/j.clinre.2012.04.003

46. Grosse B, Cassio D, Yousef N, Bernardo C, Jacquemin E, Gonzales E. Claudin1 involved in neonatal ichthyosis sclerosing cholangitis syndrome regulates hepatic paracellular permeability. Hepatology (2012) 55(4):1249-59. doi:10. 1002/hep. 24761

47. Torbenson M, Hart J, Westerhoff M, Azzam RK, Elgendi A, Mziray-Andrew $\mathrm{HC}$, et al. Neonatal giant cell hepatitis: histological and etiological findings. Am J Surg Pathol (2010) 34(10):1498-503. doi:10.1097/PAS.0b013e3181f069ab

48. Keppler D, Konig J. Hepatic secretion of conjugated drugs and endogenous substances. Semin Liver Dis (2000) 20(3):265-72. doi:10.1055/s-2000-9391

49. van de Steeg E, Stranecky V, Hartmannova H, Noskova L, Hrebicek M, Wagenaar E, et al. Complete OATP1B1 and OATP1B3 deficiency causes human Rotor syndrome by interrupting conjugated bilirubin reuptake into the liver. J Clin Invest (2012) 122(2):519-28. doi:10.1172/JCI59526

50. Kondo T, Kuchiba K, Shimizu Y. Coproporphyrin isomers in Dubin-Johnson syndrome. Gastroenterology (1976) 70(6):1117-20.

51. Shimizu Y, Naruto H, Ida S, Kohakura M. Urinary coproporphyrin isomers in Rotor's syndrome: a study in eight families. Hepatology (1981) 1(2):173-8. doi:10.1002/hep.1840010214

52. Jacquemin E. Progressive familial intrahepatic cholestasis. Clin Res Hepatol Gastroenterol (2012) 36(Suppl 1):S26-35. doi:10.1016/S2210-7401(12) 70018-9

53. Bull LN, van Eijk MJ, Pawlikowska L, DeYoung JA, Juijn JA, Liao M, et al. A gene encoding a P-type ATPase mutated in two forms of hereditary cholestasis. Nat Genet (1998) 18(3):219-24. doi:10.1038/ng0398-219

54. Kubitz R, Droge C, Stindt J, Weissenberger K, Haussinger D. The bile salt export pump (BSEP) in health and disease. Clin Res Hepatol Gastroenterol (2012) 36(6):536-53. doi:10.1016/j.clinre.2012.06.006

55. Keitel V, Burdelski M, Warskulat U, Kuhlkamp T, Keppler D, Haussinger D, et al. Expression and localization of hepatobiliary transport proteins in progressive familial intrahepatic cholestasis. Hepatology (2005) 41(5):1160-72. doi:10.1002/hep.20682

56. Schukfeh N, Metzelder ML, Petersen C, Reismann M, Pfister ED, Ure BM, et al. Normalization of serum bile acids after partial external biliary diversion indicates an excellent long-term outcome in children with progressive familial intrahepatic cholestasis. J Pediatr Surg (2012) 47(3):501-5. doi:10.1016/j. jpedsurg.2011.08.010

57. Sokol RJ, Durie PR. Recommendations for management of liver and biliary tract disease in cystic fibrosis. Cystic fibrosis foundation hepatobiliary disease consensus group. J Pediatr Gastroenterol Nutr (1999) 28(Suppl 1):S1-13. doi:10.1097/00005176-199900001-00001

58. Fregonese L, Stolk J. Hereditary alpha-1-antitrypsin deficiency and its clinical consequences. Orphanet J Rare Dis (2008) 3:16. doi:10.1186/1750-1172-3-16

59. Perlmutter DH. Alpha-1-antitrypsin deficiency: diagnosis and treatment. Clin Liver Dis (2004) 8(4):839-859,viii-ix. doi:10.1016/j.cld.2004.06.001

60. DeMeo DL, Silverman EK. Alpha1-antitrypsin deficiency. 2: genetic aspects of alpha(1)-antitrypsin deficiency: phenotypes and genetic modifiers of emphysema risk. Thorax (2004) 59(3):259-64. doi:10.1136/thx.2003.006502

61. Pittschieler K. Liver involvement in alpha1-antitrypsin-deficient phenotypes PiSZ and PiMZ. Acta Paediatr (2002) 91(2):239-40. doi:10.1111/j.1651-2227. 2002.tb01702.x

62. Bernspang E, Diaz S, Stoel B, Wollmer P, Sveger T, Piitulainen E. CT lung densitometry in young adults with alpha-1-antitrypsin deficiency. Respir Med (2011) 105(1):74-9. doi:10.1016/j.rmed.2010.06.016

63. Bove KE, Heubi JE, Balistreri WF, Setchell KD. Bile acid synthetic defects and liver disease: a comprehensive review. Pediatr Dev Pathol (2004) 7(4):315-34 doi:10.1007/s10024-002-1201-8

64. Subramaniam P, Clayton PT, Portmann BC, Mieli-Vergani G, Hadzic N. Variable clinical spectrum of the most common inborn error of bile acid metabolism - 3beta-hydroxy-delta 5-C27-steroid dehydrogenase deficiency. J Pediatr Gastroenterol Nutr (2010) 50(1):61-6. doi:10.1097/MPG. 0b013e3181b47b34

65. Sundaram SS, Bove KE, Lovell MA, Sokol RJ. Mechanisms of disease: inborn errors of bile acid synthesis. Nat Clin Pract Gastroenterol Hepatol (2008) 5(8):456-68. doi:10.1038/ncpgasthep1179

66. Clayton PT. Disorders of bile acid synthesis. J Inherit Metab Dis (2011) 34(3):593-604. doi:10.1007/s10545-010-9259-3 
67. Setchell KD, Heubi JE, Shah S, Lavine JE, Suskind D, Al-Edreesi M, et al. Genetic defects in bile acid conjugation cause fat-soluble vitamin deficiency. Gastroenterology (2013) 144(5):945-55.e6. doi:10.1053/j.gastro.2013.02.004

68. Gonzales E, Gerhardt MF, Fabre M, Setchell KD, Davit-Spraul A, Vincent I, et al. Oral cholic acid for hereditary defects of primary bile acid synthesis: a safe and effective long-term therapy. Gastroenterology (2009) 137(4): 1310-20.e1-3. doi:10.1053/j.gastro.2009.07.043

69. Rosenbloom BE, Weinreb NJ. Gaucher disease: a comprehensive review. Crit Rev Oncog (2013) 18(3):163-75. doi:10.1615/CritRevOncog.2013006060

70. Bennett LL, Mohan D. Gaucher disease and its treatment options. Ann Pharmacother (2013) 47(9):1182-93. doi:10.1177/1060028013500469

71. Wildhaber BE. Biliary atresia: 50 years after the first kasai. ISRN Surg (2012) 2012:132089. doi:10.5402/2012/132089

72. Adeva M, El-Youssef M, Rossetti S, Kamath PS, Kubly V, Consugar MB, et al. Clinical and molecular characterization defines a broadened spectrum of autosomal recessive polycystic kidney disease (ARPKD). Medicine (Baltimore) (2006) 85(1):1-21. doi:10.1097/01.md.0000200165.90373.9a

73. Krall P, Pineda C, Ruiz P, Ejarque L, Vendrell T, Camacho JA, et al. Costeffective PKHD1 genetic testing for autosomal recessive polycystic kidney disease. Pediatr Nephrol (2014) 29(2):223-34. doi:10.1007/s00467-013-2657-7

74. Patterson MC, Hendriksz CJ, Walterfang M, Sedel F, Vanier MT, Wijburg F. Recommendations for the diagnosis and management of Niemann-Pick disease type C: an update. Mol Genet Metab (2012) 106(3):330-44. doi:10. 1016/j.ymgme.2012.03.012

75. Zhang B, Porto AF. Cholesteryl ester storage disease: protean presentations of lysosomal acid lipase deficiency. J Pediatr Gastroenterol Nutr (2013) 56(6):682-5. doi:10.1097/MPG.0b013e31828b36ac

76. Fellman V, Kotarsky H. Mitochondrial hepatopathies in the newborn period. Semin Fetal Neonatal Med (2011) 16(4):222-8. doi:10.1016/j.siny.2011.05.002

77. Wong LJ, Scaglia F, Graham BH, Craigen WJ. Current molecular diagnostic algorithm for mitochondrial disorders. Mol Genet Metab (2010) 100(2):111-7. doi:10.1016/j.ymgme.2010.02.024

78. Lu YB, Kobayashi K, Ushikai M, Tabata A, Iijima M, Li MX, et al. Frequency and distribution in East Asia of 12 mutations identified in the SLC25A13 gene of Japanese patients with citrin deficiency. J Hum Genet (2005) 50(7):338-46. doi:10.1007/s10038-005-0262-8

79. Kimura A, Kage M, Nagata I, Mushiake S, Ohura T, Tazawa Y, et al. Histological findings in the livers of patients with neonatal intrahepatic cholestasis caused by citrin deficiency. Hepatol Res (2010) 40(4):295-303. doi:10.1111/j. 1872-034X.2009.00594.x

80. Song YZ, Zhang ZH, Lin WX, Zhao XJ, Deng M, Ma YL, et al. SLC25A13 gene analysis in citrin deficiency: sixteen novel mutations in East Asian patients, and the mutation distribution in a large pediatric cohort in China. PLoS One (2013) 8(9):e74544. doi:10.1371/journal.pone.0074544

81. Moser AB, Kreiter N, Bezman L, Lu S, Raymond GV, Naidu S, et al. Plasma very long chain fatty acids in 3,000 peroxisome disease patients and 29,000 controls. Ann Neurol (1999) 45(1):100-10. doi:10.1002/1531-8249(199901)45: $1<100:$ :AID-ART16>3.0.CO;2-U

82. Moser HW, Moser AB. Peroxisomal disorders: overview. Ann N Y Acad Sci (1996) 804:427-41. doi:10.1111/j.1749-6632.1996.tb18634.x

83. Santra S, Baumann U. Experience of nitisinone for the pharmacological treatment of hereditary tyrosinaemia type 1. Expert Opin Pharmacother (2008) 9(7):1229-36. doi:10.1517/14656566.9.7.1229

84. de Laet C, Dionisi-Vici C, Leonard JV, McKiernan P, Mitchell G, Monti L, et al. Recommendations for the management of tyrosinaemia type 1. Orphanet J Rare Dis (2013) 8:8. doi:10.1186/1750-1172-8-8

85. Mayatepek E, Hoffmann B, Meissner T. Inborn errors of carbohydrate metabolism. Best Pract Res Clin Gastroenterol (2010) 24(5):607-18. doi:10. 1016/j.bpg.2010.07.012

86. Jaeken J. Congenital disorders of glycosylation (CDG): it's (nearly) all in it! J Inherit Metab Dis (2011) 34(4):853-8. doi:10.1007/s10545-011-9299-3

87. Freeze HH. Congenital disorders of glycosylation: CDG-I, CDG-II, and beyond. Curr Mol Med (2007) 7(4):389-96. doi:10.2174/156652407780831548

88. Freeze HH. Understanding human glycosylation disorders: biochemistry leads the charge. J Biol Chem (2013) 288(10):6936-45. doi:10.1074/jbc.R112.429274

89. Linssen M, Mohamed M, Wevers RA, Lefeber DJ, Morava E. Thrombotic complications in patients with PMM2-CDG. Mol Genet Metab (2013) 109(1):107-11. doi:10.1016/j.ymgme.2013.02.006
90. Hanna CE, Krainz PL, Skeels MR, Miyahira RS, Sesser DE, LaFranchi SH. Detection of congenital hypopituitary hypothyroidism: ten-year experience in the northwest regional screening program. J Pediatr (1986) 109(6):959-64. doi:10.1016/S0022-3476(86)80276-1

91. Binder G, Martin DD, Kanther I, Schwarze CP, Ranke MB. The course of neonatal cholestasis in congenital combined pituitary hormone deficiency. J Pediatr Endocrinol Metab (2007) 20(6):695-702. doi:10.1515/JPEM.2007.20. 6.695

92. Karnsakul W, Sawathiparnich P, Nimkarn S, Likitmaskul S, Santiprabhob J, Aanpreung P. Anterior pituitary hormone effects on hepatic functions in infants with congenital hypopituitarism. Ann Hepatol (2007) 6(2): 97-103.

93. Hsieh MH, Pai W, Tseng HI, Yang SN, Lu CC, Chen HL. Parenteral nutritionassociated cholestasis in premature babies: risk factors and predictors. Pediatr Neonatol (2009) 50(5):202-7. doi:10.1016/S1875-9572(09)60064-4

94. Rand EB, Karpen SJ, Kelly S, Mack CL, Malatack JJ, Sokol RJ, et al. Treatment of neonatal hemochromatosis with exchange transfusion and intravenous immunoglobulin. J Pediatr (2009) 155(4):566-71. doi:10.1016/j.jpeds. 2009.04.012

95. Hon KL, Leung AK. Neonatal lupus erythematosus. Autoimmune Dis (2012) 2012:301274. doi:10.1155/2012/301274

96. Lehmberg K, Ehl S. Diagnostic evaluation of patients with suspected haemophagocytic lymphohistiocytosis. Br J Haematol (2013) 160(3):275-87. doi:10.1111/bjh.12138

97. Xu XJ, Tang YM, Song $\mathrm{H}$, Yang SL, Xu WQ, Zhao N, et al. Diagnostic accuracy of a specific cytokine pattern in hemophagocytic lymphohistiocytosis in children. J Pediatr (2012) 160(6):984.e-90.e. doi:10.1016/j.jpeds.2011.11. 046

98. Kosters A, Karpen SJ. The role of inflammation in cholestasis: clinical and basic aspects. Semin Liver Dis (2010) 30(2):186-94. doi:10.1055/ s-0030- 1253227

99. Bellomo-Brandao MA, Andrade PD, Costa SC, Escanhoela CA, Vassallo J, Porta G, et al. Cytomegalovirus frequency in neonatal intrahepatic cholestasis determined by serology, histology, immunohistochemistry and PCR. World J Gastroenterol (2009) 15(27):3411-6. doi:10.3748/wjg.15.3411

100. Robino L, Machado K, Montano A. [Neonatal cholestasis due to congenital toxoplasmosis. Case report]. Arch Argent Pediatr (2013) 111(4):e105-8. doi:10. 1590/S0325-00752013000400020

101. Bernard O, Franchi-Abella S, Branchereau S, Pariente D, Gauthier F, Jacquemin E. Congenital portosystemic shunts in children: recognition, evaluation, and management. Semin Liver Dis (2012) 32(4):273-87. doi:10.1055/ s-0032-1329896

102. Avagyan S, Klein M, Kerkar N, Demattia A, Blei F, Lee S, et al. Propranolol as a first-line treatment for diffuse infantile hepatic hemangioendothelioma. J Pediatr Gastroenterol Nutr (2013) 56(3):e17-20. doi:10.1097/MPG 0b013e31824e50b7

103. Horii KA, Drolet BA, Frieden IJ, Baselga E, Chamlin SL, Haggstrom AN, et al. Prospective study of the frequency of hepatic hemangiomas in infants with multiple cutaneous infantile hemangiomas. Pediatr Dermatol (2011) 28(3):245-53. doi:10.1111/j.1525-1470.2011.01420.x

104. Arnell H, Fischler B. Population-based study of incidence and clinical outcome of neonatal cholestasis in patients with Down syndrome. J Pediatr (2012) 161(5):899-902. doi:10.1016/j.jpeds.2012.04.037

105. Smith H, Galmes R, Gogolina E, Straatman-Iwanowska A, Reay K, Banushi $\mathrm{B}$, et al. Associations among genotype, clinical phenotype, and intracellular localization of trafficking proteins in ARC syndrome. Hum Mutat (2012) 33(12):1656-64. doi:10.1002/humu.22155

106. Eastham KM, McKiernan PJ, Milford DV, Ramani P, Wyllie J, van't Hoff W, et al. ARC syndrome: an expanding range of phenotypes. Arch Dis Child (2001) 85(5):415-20. doi:10.1136/adc.85.5.415

107. Drivdal M, Trydal T, Hagve TA, Bergstad I, Aagenaes O. Prognosis, with evaluation of general biochemistry, of liver disease in lymphoedema cholestasis syndrome 1 (LCS1/Aagenaes syndrome). Scand J Gastroenterol (2006) 41(4):465-71. doi:10.1080/00365520500335183

108. Ruemmele FM, Muller T, Schiefermeier N, Ebner HL, Lechner S, Pfaller K, et al. Loss-of-function of MYO5B is the main cause of microvillus inclusion disease: 15 novel mutations and a CaCo-2 RNAi cell model. Hum Mutat (2010) 31(5):544-51. doi:10.1002/humu.21224 
109. van der Linden MH, Creemers S, Pieters R. Diagnosis and management of neonatal leukaemia. Semin Fetal Neonatal Med (2012) 17(4):192-5. doi:10. 1016/j.siny.2012.03.003

110. Hulkova H, Elleder M. Distinctive histopathological features that support a diagnosis of cholesterol ester storage disease in liver biopsy specimens. Histopathology (2012) 60(7):1107-13. doi:10.1111/j.1365-2559.2011. 04164.x

111. Porto AF. Lysosomal acid lipase deficiency: diagnosis and treatment of Wolman and cholesteryl ester storage diseases. Pediatr Endocrinol Rev (2014) 12(Suppl 1):125-32.
Conflict of Interest Statement: The authors declare that the research was conducted in the absence of any commercial or financial relationships that could be construed as a potential conflict of interest. No external funding was secured for this study.

Copyright (C) 2015 Götze, Blessing, Grillhösl, Gerner and Hoerning. This is an openaccess article distributed under the terms of the Creative Commons Attribution License (CC BY). The use, distribution or reproduction in other forums is permitted, provided the original author(s) or licensor are credited and that the original publication in this journal is cited, in accordance with accepted academic practice. No use, distribution or reproduction is permitted which does not comply with these terms. 